\title{
NITROGÊNIO E COBRE NA PRODUÇÃO DE MUDAS \\ DE CITROS EM DIFERENTES PORTA-ENXERTOS $\left({ }^{1}\right)$
}

\author{
DIRCEU MATTOS Jr. $\left({ }^{2}, 5\right)$; UIRÁ MANZOLLI RAMOS $\left({ }^{2}\right)$; \\ JOSÉ ANTÔNIO QUAGGIO ( $\left.{ }^{3}\right)$; PEDRO ROBERTO FURLANI $\left({ }^{4}\right)$
}

\begin{abstract}
RESUMO
A citricultura brasileira é uma atividade de destaque na pauta econômica do País. O seu crescimento e manutenção requerem a produção de 15-20 milhões de mudas anualmente. Em vista das características dos viveiros e das variedades porta-enxertos e copas, há a necessidade de se estabelecer um manejo nutricional adequado dessas plantas. O estudo teve o objetivo de avaliar o suprimento de $\mathrm{N}$ e $\mathrm{Cu}$ e o desenvolvimento e estado nutricional de mudas de laranjeira 'Pêra', sobre porta-enxertos de limoeiro 'Cravo' e tangerineira 'Sunki'. Foram aplicados dois níveis de N $=120$ e $240 \mathrm{mg} \mathrm{L}^{-1}$, e quatro de $\mathrm{Cu}=0,5,10$ e $20 \mathrm{mg} \mathrm{L}^{-1}$ (Cu-EDTA) via fertirrigação, entre o transplantio de porta-enxertos e a finalização da muda. O porta-enxerto de 'Cravo' possui maior vigor comparado à 'Sunki' com base na produção de massa seca e tamanho das plantas. O maior desenvolvimento das mudas foi obtido com a solução de fertirrigação com $240 \mathrm{mg} \mathrm{L}^{-1}$ de $\mathrm{N}$ e 5 a $10 \mathrm{mg} \mathrm{L}^{-1}$ de $\mathrm{Cu}$. Houve efeito depressivo na concentração de $20 \mathrm{mg} \mathrm{L}^{-1}$ de $\mathrm{Cu}$, associado a teores de $\mathrm{Cu}$ das folhas de $20 \mathrm{mg} \mathrm{kg}^{-1}$ e das raízes de $50 \mathrm{mg} \mathrm{kg}^{-1}$. Esse prejuízo foi menor com o maior fornecimento de N. Da mesma forma, o pegamento de borbulhas da laranjeira 'Pêra' foi ótimo nas doses intermediárias de $\mathrm{Cu}$. A demanda de $\mathrm{Cu}$ foi maior para mudas sobre 'Sunki' na maior dose de $\mathrm{N}$ e o excesso desse micronutriente reduziu a absorção de $\mathrm{Mn}$. Os teores de $\mathrm{Cu}$ foram maiores nas raízes da porção superior do recipiente de produção das muda, o que coincidiu com a maior adsorção do elemento no substrato, com máximo acima de $300 \mathrm{mg} \mathrm{kg}^{-1}$ de $\mathrm{Cu}$.
\end{abstract}

Palavras-chave: Citrus, nutrição mineral, fertirrigação, micronutrientes, propagação.

$\left({ }^{1}\right)$ Parte da Dissertação de mestrado do segundo autor, defendida no Programa de Pós-graduação em Agricultura Tropical e Subtropical do Instituto Agronômico. Recebido para publicação em 2 de junho de 2008 e aceito em 3 de agosto de 2009.

$\left({ }^{2}\right)$ Centro de Citricultura Sylvio Moreira, Instituto Agronômico, Caixa Postal 4, 13490-970 Cordeirópolis (SP). E-mail: ddm@centrodecitricultura.br $\left(^{*}\right)$ Autor correspondente); umanzolli@uol.com.br.

$\left({ }^{3}\right)$ Centro de Solos e Recursos Agroambientais, Instituto Agronômico, Av. Barão de Itapura, 1481, 13020-092 Campinas (SP). E-mail: quaggio@iac.sp.gov.br.

$\left({ }^{4}\right)$ Conplant, R. Francisco Andreo Aledo, 22, 13084-200 Campinas (SP). E-mail: pfurlani@conplant.com.br.

$\left({ }^{5}\right)$ Bolsista CNPq. 


\title{
ABSTRACT \\ NITROGEN AND COPPER FOR CITRUS NURSERY PRODUCTION ON TWO DIFFERENT ROOTSTOCKS
}

\begin{abstract}
The citrus industry is an important economical activity in Brazil. The increase and maintenance of citrus groves require the production of 15-20 million nursery plants yearly. Due to the type of nurseries and horticultural characteristics of rootstocks and scions the development of guidelines for best nutrient management of these plants is requiered. This research evaluated the supply of $\mathrm{N}$ and $\mathrm{Cu}$, and the growth and nutritional status of 'Pêra' sweet orange nursery trees grafted on 'Rangpur lime' and 'Sunki' mandarin rootstocks. Two levels of $\mathrm{N}\left(120\right.$ and $\left.240 \mathrm{mg} \mathrm{L}^{-1}\right)$ and four of $\mathrm{Cu}\left(0,5,10\right.$ and $20 \mathrm{mg} \mathrm{L}^{-1}$; Cu-EDTA) were applied via fertigation from seedlings transplantation to finalization of nursery plants. The Rangpur lime demonstrated greater vigour compared to the 'Sunki', based on production of dry mass and plant size. Better plant growth was attained at $240 \mathrm{mg} \mathrm{L}^{-1}$ of $\mathrm{N}$ and 5 to $10 \mathrm{mg} \mathrm{L}^{-1}$ of $\mathrm{Cu}$, whereas a negative growth was observed with $20 \mathrm{mg} \mathrm{L}^{-1}$ of $\mathrm{Cu}$, which was associated with $\mathrm{Cu}$ concentrations in the leaf tissue of $20 \mathrm{mg} \mathrm{kg}^{-1}$ and root of $50 \mathrm{mg} \mathrm{kg}^{-1}$. This negative effect was minimized with greater $\mathrm{N}$ supply. Similarly, bud take was optimum with intermediate Cu supply both rootstocks on both rootstocks. Copper demand of 'Pêra' nursery plants was greater for those on 'Sunki' mandarin rootstock and at $200 \mathrm{mg} \mathrm{L}^{-1}$ of $\mathrm{N}$ fertigation. Excess of $\mathrm{Cu}$ also reduced $\mathrm{Mn}$ uptake by plants. Greater $\mathrm{Cu}$ concentration was observed in root tissues from the upper part of nursery bags, compared to the lower part which, was in line with the $\mathrm{Cu}$ adsorption in the substrate, as indicated by a maximum concentration of $310 \mathrm{mg} \mathrm{kg}^{-1}$ of $\mathrm{Cu}$.
\end{abstract}

Key words: Citrus, mineral nutrition, fertigation, micronutrients, propagation.

\section{INTRODUÇÃO}

A citricultura brasileira produz 18 milhões de toneladas anuais de laranjas, o que representa $28 \%$ do total mundial; são cerca de 800 mil hectares cultivados no País (FAO, 2008), dos quais, $70 \%$ a $80 \%$ localizam-se no Estado de São Paulo. A manutenção desse parque requer um grande número de mudas para o plantio de pomares, o que é evidenciado pela produção de mais de 22 milhões de mudas por cerca de 550 viveiros comerciais no Estado de São Paulo em 2008 (FundeCITRUS, 2008).

Apesar da significativa produção dos viveiros, são observadas dificuldades para o manejo nutricional, cujas condições de ambiente, características dos substratos e das variedades exigem a adoção de estratégias adequadas para o suprimento de nutrientes em quantidade e nos períodos determinados pela demanda das plantas (CARvalHo et al., 2005).

Informações disponíveis na literatura internacional deram subsídios ao setor para estabelecer a demanda e a adubação de $\mathrm{N}$ e de outros nutrientes pelas mudas, além de sugerir fontes e modos de aplicação de fertilizantes (Williamson e Castle, 1989; Castle e Rouse, 1990; Coetzee et al., 1993; Maust e Williamson, 1994). A partir daí, pesquisas dentro das condições estabelecidas no Brasil trouxeram novas contribuições para o avanço do setor (CARvalho, 1994; Joaquim, 1997; Perin et al., 1999; Decarlos Neto et al., 2002; Boaventura et al., 2004; Ruschel et al., 2004; GirARDI et al., 2005). Desses trabalhos, destacam-se estudos sobre respostas dos citros no viveiro ao $\mathrm{N}, \mathrm{P}, \mathrm{K}$ e $\mathrm{Ca}$, uso de diferentes fontes de $\mathrm{N}$, fontes solúveis e de liberação lenta de nutrientes, demanda e balanço de nutrientes em diferentes manejos. Contudo, pouco se tratou do fornecimento de micronutrientes (BOAVENTURA, 2003; FERRAREZI et al., 2007; BordignON, 2008; MATTOS JúNIOR et al., 2008).

Teores elevados de cobre $(\mathrm{Cu})$ nas folhas e também nas demais partes de mudas de laranjeira 'Valência' sugerem que a exigência de mudas para este nutriente é superior àquela de plantas adultas (BOAVENTURA, 2003). Em consequência da aplicação de maiores doses de $\mathrm{N}$ visando ao rápido crescimento das mudas, têm-se reportado problemas nos viveiros associados à deficiência de $\mathrm{Cu}$ causada pelo excesso de $\mathrm{N}$ nos viveiros (Almeida et al., 2007a, b). Também, pouco se dispõe de informações acerca do manejo de $\mathrm{N}$ e $\mathrm{Cu}$ para a produção de mudas.

A relação entre a severidade da deficiência de cobre em plantas e o suprimento em excesso de $\mathrm{N}$ é caracterizada por interações não específicas pelo aumento do crescimento e do consequente aumento da demanda, e também por interações específicas sobre a disponibilidade e mobilidade do cobre na planta. Neste contexto, GILBERT (1951) discute que a atividade de $\mathrm{Cu}$ no metabolismo vegetal é inversamente proporcional à concentração do íon ligado a complexos protéicos, $\mathrm{o}$ que determina reduções de transporte eletrônico, atividade enzimática e fotossíntese. Por outro lado, o excesso de $\mathrm{Cu}$ afeta vários processos bioquímicos e ocasiona distúrbios do metabolismo, resultando em inibição do crescimento, ou desenvolvimento anormal (Fernandes e Henriques, 1991). 
Neste contexto, o objetivo desse trabalho foi avaliar o fornecimento de $\mathrm{N}$ e $\mathrm{Cu}$ via fertirrigação, o desenvolvimento e estado nutricional de mudas de laranjeira 'Pêra' produzidas sobre os porta-enxertos de limoeiro 'Cravo' e tangerineira 'Sunki' em substrato, entre a fase do transplantio do portaenxerto e a finalização da muda.

\section{MATERIAL E MÉTODOS}

$\mathrm{O}$ experimento foi desenvolvido em viveiro comercial de citros, em Conchal (SP). Estudou-se a produção de mudas de laranjeira 'Pêra' [C. sinensis (L.) Osbeck] sobre: a) dois porta-enxertos: limoeiro 'Cravo' [C. limonia (L.) Osbeck] e tangerineira 'Sunki' [Citrus sunki (Hayata) hort. ex Tanaka], fertirrigadas com b) dois níveis de $\mathrm{N}$ (120 e $240 \mathrm{mg} \mathrm{L}^{-1}$ ) e c) quatro níveis de $\mathrm{Cu}\left(0,5,10\right.$ e $\left.20 \mathrm{mg} \mathrm{L}^{-1}\right)$. Essas concentrações, assim como aquelas de outros mutrientes da solução de fertirigação apresentada a seguir, foram estabelecidas com base em pesquisas e recomendações médias utilizadas por viveiros comerciais (BOAVENTURA, 2003; Bataglia et al., 2008). A dose $\mathrm{N}=120 \mathrm{mg} \mathrm{L}^{-1}$ representou uma concentração baixa, enquanto $\mathrm{N}=$ $240 \mathrm{mg} \mathrm{L}^{-1}$, uma concentração alta do nutriente no sistema de manejo. Esse procedimento possibilitou o estudo das respostas das mudas no viveiro ao fornecimento de $\mathrm{Cu}$. Ainda, para o estabelecimento das composições das soluções, adotaram-se combinações de sais solúveis para alcançar menores variações de concentração de nutrientes (exceto $\mathrm{N}$ e $\mathrm{Cu}$ ) e condutividade elétrica nas soluções de fertirrigação. Utilizou-se o delineamento inteiramente casualizado em esquema fatorial $2 \times 2 \times 4$, com três repetições. As parcelas experimentais foram compostas por 27 plantas.

Porta-enxertos de 'Cravo' e 'Sunki', com cerca de quatro meses de idade após a semeadura, foram transplantados em 15/1/2007 para recipientes do tipo sacola plástica em polietileno preto, com capacidade de $7,0 \mathrm{dm}^{3}$. Foi utilizado o substrato à base de casca de Pinus e sem adição de $\mathrm{Cu}$ (Rendimax Citrus ${ }^{\circledR}$ da Eucatex, Paulínea, SP), com as seguintes características físicas e químicas (teor total): umidade volumétrica $=55 \%$ ( 0 atm de tensão); densidade seca $=294,5 \mathrm{~g} \mathrm{~kg}^{-1}$; distribuição de partículas $=20 \%(2,0-$ $4,0 \mathrm{~mm})$ e $34 \%$ (>4,0 mm); $\mathrm{pH}\left(\mathrm{CaCl}_{2}\right)=4,8 ; \mathrm{CE}=1,5$ $\mathrm{dS} \mathrm{m}{ }^{-1} ; \mathrm{C}$-org = $339 \mathrm{mg} \mathrm{kg}^{-1}$ (por Walkley-Black); $\mathrm{N}=$ $7,5 \mathrm{mg} \mathrm{kg}^{-1}$ (por Kjeldahl); $\mathrm{P}=2,0, \mathrm{~K}=1,2, \mathrm{Ca}=7,4$, $\mathrm{Mg}=16,1$ e $\mathrm{S}=0,7, \mathrm{em} \mathrm{g} \mathrm{kg}^{-1}$, e B = 8,2, $\mathrm{Fe}=9,2, \mathrm{Cu}=$ $18,3, \mathrm{Mn}=175,6$ e $\mathrm{Zn}=9,2$, em mg kg${ }^{-1}$ (após digestão nítrico-perclórico e determinação por plasma de argônio acoplado indutivamente - ICP-AE). O teor de $\mathrm{Cu}$ em extrato saturado $1: 1,5$ (SONNENVELD e VAN ELDEREN, 1994) foi $<0,01 \mathrm{mg} \mathrm{L}^{-1}$.
Os porta-enxertos desenvolveram-se no viveiro até 93 dias após o transplantio, quando foram enxertados com borbulhas da laranjeira 'Pêra'. Logo após a enxertia, realizou-se o forçamento da borbulha pelo método de curvamento da haste do porta-enxerto, que foi cortada aos 146 dias. A formação das mudas foi finalizada aos 162 dias após a enxertia, quando se totalizaram 254 dias após o transplantio no viveiro.

Além do $\mathrm{N}$ e do $\mathrm{Cu}$, o manejo de nutrientes feito com a aplicação de solução nutritiva, via água de irrigação, cujas concentrações, em $\mathrm{mg} \mathrm{L}^{-1}$, foram: $\mathrm{P}(30), \mathrm{K}$ (120 ou 216), Ca (90 ou 120), Mg (30), S (40), B $(0,55)$, Fe $(1,8)$, Mn $(0,54)$, Zn $(0,23)$ e Mo $(0,10)$. Foram utilizados sais solúveis para o preparo das soluções finais de trabalho, cujas relacões $\mathrm{N}_{-} \mathrm{NH}_{4}{ }^{+} /$ $\mathrm{N}$-total e condutividade elétrica foram $10,0 \%$ e 1,36 $\mathrm{dS} \mathrm{m} \mathrm{m}^{-1}$ para aquela com $\mathrm{N}=120 \mathrm{mg} \mathrm{L}^{-1}$ e $18,3 \%$ e 1,95 $\mathrm{dS} \mathrm{m}{ }^{-1}$ para $\mathrm{N}=240 \mathrm{mg} \mathrm{L}^{-1}$ respectivamente. As concentrações de $\mathrm{K}$ e Ca variaram para ajuste da composição da solução com doses diferenciais de $\mathrm{N}$. A fertirrigação, feita individualmente por sacola com $250 \mathrm{~mL}$ por planta, ocorreu 2-3 vezes por semana procurando-se adequar a demanda da planta com o crescimento.

O fornecimento de nutrientes ocorreu com 36 aplicações da fertirrigação antes da enxertia e 62 aplicações após a enxertia das mudas. Assim, as quantidades totais aplicadas, para a condição de baixo suprimento de $\mathrm{N}\left(120 \mathrm{mg} \mathrm{L}^{-1}\right)$, em mg por sacola, foram: N (2940), K (2940), P (735), Ca (2205), Mg (735), S (980), B $(13,5), \mathrm{Fe}(44,1), \mathrm{Mn}$ $(13,2)$, Zn $(5,6)$ e Mo $(2,5)$, enquanto para o alto suprimento de $\mathrm{N}\left(240 \mathrm{mg} \mathrm{L}^{-1}\right)$, foram: N (5880), K (5292) e Ca (2940) mg por sacola; as quantidades de $\mathrm{P}, \mathrm{Mg}$, $\mathrm{S}$ e micronutrientes, exceto $\mathrm{Cu}$, foram as mesmas que aquelas anteriores. Para $\mathrm{Cu}$, foram fornecidos $0,123,245$ e $490 \mathrm{mg}$ por sacola, conforme as doses testadas.

A coleta de plantas para a avaliação do crescimento e análise do tecido vegetal foi também feita aos 81 dias (12 dias antes da enxertia) e 254 dias (por ocasião da finalização das mudas) após o transplantio. As plantas coletadas foram divididas em raízes (metades superior e inferior da sacola), caule e folhas, cujas partes foram lavadas com água, solução detergente $(0,1 \% \mathrm{v} / \mathrm{v}), \mathrm{HCl} 0,01 \mathrm{~N}$, novamente lavadas em água e água desionizada. Após a lavagem as amostras foram secadas em estufa a $60^{\circ} \mathrm{C}$, por $24 \mathrm{~h}$. Foram medidas a altura, o diâmetro de caule ao nível do substrato (d) e a massa seca das raízes, caule e folhas. A razão da massa seca da parte aérea : raízes (PA/R) das plantas foi calculada para as duas avaliações realizadas. 
As raízes e folhas foram moídas em moinho tipo Wiley com peneira de $1 \mathrm{~mm}$ de abertura. O material vegetal moído foi digerido por digestão via úmida (BAtAglia et al., 1983). Os teores totais dos nutrientes foram obtidos após suas quantificações feitas em ICP-AE. O N total foi determinado após digestão, passagem por microdestilador Kjeldahl e titulação com solução de ácido sulfúrico padronizado. Porções do substrato das camadas superior (camada de 0-20 cm) e inferior (camada de 20-40 cm) das sacolas do mesmo tratamento dentro de porta-enxertos foram coletadas no final do experimento, secos e moídos para determinação dos teores totais de $\mathrm{Cu}, \mathrm{Fe}, \mathrm{Mn}$ e $\mathrm{Zn}$ nas amostras compostas.

O pegamento das borbulhas foi feito pela contagem dos brotos desenvolvidos da laranjeira com cerca de $5 \mathrm{~cm}$ de comprimento. Esta avaliação foi realizada aos 51 dias e depois aos 92 dias após a enxertia.

A análise de variância dos fatores estudados e interações foi realizada utilizando-se o modo GLM do pacote estatístico SAS ${ }^{\circledR}$ (SAS Institute, 1996). Na análise de variância dos teores totais dos micronutrientes no substrato, foi considerada a camada de amostragem como fator de causa de variação independentemente do tipo de porta-enxerto estudado. Modelos lineares de resposta foram ajustados para variáveis dependentes utilizando-se o modo REG do mesmo pacote.

\section{RESULTADOS E DISCUSSÃO}

O crescimento dos porta-enxertos de 'Cravo' e de 'Sunki' demonstrou o maior vigor do primeiro no viveiro $(P<0,01$; Tabela 1$)$. As médias da massa seca de folhas e das haste de plantas de 'Cravo' foram cerca de $40 \%$ maiores comparadas àquelas de 'Sunki'. A maior diferença entre os porta-enxertos foi observada para a produção de raízes, principalmente, àquelas da parte inferior da sacola cuja média, para o 'Cravo' (1,5 g), foi $75 \%$ maior, o que determinou a menor relação parte aérea : raízes (PA/R) do 'Cravo' e o maior diâmetro de seu caule, em relação a 'Sunki' (Tabela 1). O maior vigor do 'Cravo' comparado com 'Sunki' e a outros portaenxertos é também observado nos viveiros, sendo este efeito provavelmente decorrente de diferenças genéticas entre as variedades (CARVALHO, 1994; Pompeu Junior., 2005; Bordignon, 2008).

As doses de $\mathrm{N}$ aplicadas na fertirrigação não influenciaram o desenvolvimento das plantas até a enxertia, pois, além de diâmetro de caule semelhantes, ambos os porta-enxertos produziram quantidades equivalentes de massa seca total $(P>0,05$; Tabela 1$)$, comparáveis àquelas obtidas para porta-enxertos de 'Cravo' e citrumelo 'Swingle' com a aplicação de solução contendo $196 \mathrm{mg} \mathrm{L}^{-1}$ de N (BOAVENTURA et al., 2004). O crescimento das mudas de citros é menos intenso nos meses mais frios se comparado àquele durante os meses mais quentes. Essa diferença foi discutida por SCHAFER et al. (2006), em estudo com porta-enxertos cítricos em fase inicial do viveiro, e também verificada por BATAGLiA et al. (2008), cujos dados de crescimento e concentração de $\mathrm{N}$ em portaenxertos de 'Cleópatra', 'Cravo' e 'Sunki' são maiores para plantas produzidas no período do verão, se comparados àquelas produzidas no inverno. Assim, é possível que, entre fevereiro e setembro, a resposta às doses de $\mathrm{N}$ tenha sido minimizada no presente estudo. Também, em função do número de aplicações da fertirrigação, as quantidades de $\mathrm{N}$ supridas em cada condição podem ter atendido a demanda dos porta-enxertos. CARVAlHo e Souza (1996) verificaram que as aplicações da adubação com $\mathrm{N}$ em sementeira, na frequência maior que uma vez por semana, ou maior que duas vezes por semana, respectivamente, para 'Cravo' e 'Cleópatra', não influenciaram seu crescimento. Embora não se tenha realizado o controle no presente estudo, é possível que na dose alta de $\mathrm{N}$ possa ter ocorrido maiores perdas do nutriente na sacola por lixiviação.

O suprimento do $\mathrm{Cu}$-EDTA, na dose até de $5 \mathrm{mg} \mathrm{L}^{-1}$, determinou um aumento da massa seca das plantas em relação à testemunha $(P<0,05$; Tabela 1). Doses de $\mathrm{Cu}$ maiores que $5 \mathrm{mg} \mathrm{L}^{-1}$ causaram efeito negativo sobre aquelas características, o que indica, toxicidade do nutriente. Recente estudo demonstrou que a máxima produção de massa seca das plantas de 'Cravo' e de 'Sunki', fertirrigadas com solução com $\mathrm{Cu}$-EDTA, foi obtida na dose de $3,0 \mathrm{mg} \mathrm{L}^{-1}$ de $\mathrm{Cu}$ durante a fase de sementeira; já na fase entre o transplantio e a enxertia, a resposta foi linear na dose até de 7,5 $\mathrm{mg} \mathrm{L}^{-1}$ de $\mathrm{Cu}$ (Bordignon, 2008).

$\mathrm{Na}$ fase seguinte do estudo, o crescimento da laranjeira 'Pêra' /'Cravo' foi também maior $(P<0,01$; Tabela 2); observaram-se $\mathrm{PA}=29,8 \pm 4,1 \mathrm{~g}$ planta $^{-1}, \mathrm{R}=14,8 \pm 2,0 \mathrm{~g} \mathrm{planta}^{-1} \mathrm{e} \mathrm{d}=11,5 \pm 0,7 \mathrm{~mm}$, e para a 'Pêra'/'Sunki', PA $=23,8 \pm 3,6 \mathrm{~g} \mathrm{planta}^{-1}$, $\mathrm{R}=10,3 \pm 1,3 \mathrm{~g} \mathrm{planta}^{-1}$ e $\mathrm{d}=9,0 \pm 0,4 \mathrm{~mm}$. As doses de $\mathrm{N}$ e $\mathrm{Cu}$, bem como sua interação influenciaram a resposta das mudas. A massa da parte aérea dos porta-enxertos foi maior no tratamento com $240 \mathrm{mg} \mathrm{L}^{-1}$ de N $(P<0,05 ;$ Tabela 2$)$. Por outro lado, houve um decréscimo na produção de massa seca de raízes, o que determinou a relação $\mathrm{PA} / \mathrm{R}$ para 'Pêra'/ 'Cravo' de 1,9 e de 2,1 (médias dentro de portaenxertos; $n=24$ ). 
Tabela 1. Crescimento de porta-enxertos, aos 81 dias de idade após o transplantio, fertirrigados com diferentes doses de nitrogênio e cobre

\begin{tabular}{|c|c|c|c|c|c|c|c|c|c|}
\hline \multicolumn{2}{|c|}{ Tratamento } & \multicolumn{6}{|c|}{ Produção de massa seca $\left({ }^{1}\right)$} & \multicolumn{2}{|c|}{ Tamanho $\left({ }^{2}\right)$} \\
\hline $\mathrm{N}$ & $\mathrm{Cu}$ & Folha & Haste & Raiz inferior & Raiz superior & Raiz total & Total & Diâmetro & $\mathrm{PA} / \mathrm{R}$ \\
\hline \multirow{2}{*}{\multicolumn{2}{|c|}{$\mathrm{mg} \mathrm{L}^{-1}$}} & \multirow{2}{*}{\multicolumn{6}{|c|}{ 'Cravo' }} & \multirow{2}{*}{\multicolumn{2}{|c|}{$\mathrm{mm}$}} \\
\hline & & & & & & & & & \\
\hline 120 & 0 & 5,9 & 5,3 & 1,5 & 3,0 & 4,6 & 15,7 & 6,2 & 2,5 \\
\hline 120 & 5 & 7,8 & 6,7 & 1,8 & 3,2 & 5,0 & 19,6 & 6,2 & 2,9 \\
\hline 120 & 10 & 7,1 & 6,1 & 1,5 & 3,1 & 4,6 & 17,8 & 6,1 & 2,9 \\
\hline 120 & 20 & 7,0 & 6,1 & 1,5 & 3,1 & 4,6 & 17,7 & 6,2 & 2,8 \\
\hline 240 & 0 & 7,3 & 5,7 & 1,3 & 3,4 & 4,8 & 17,8 & 6,0 & 2,7 \\
\hline 240 & 5 & 8,0 & 6,8 & 1,8 & 3,1 & 4,9 & 19,8 & 6,0 & 3,1 \\
\hline 240 & 10 & 7,0 & 6,2 & 1,4 & 2,9 & 4,3 & 17,4 & 6,4 & 3,1 \\
\hline 240 & 20 & 6,8 & 6,0 & 1,3 & 2,9 & 4,2 & 17,0 & 6,0 & 3,1 \\
\hline \multirow[t]{2}{*}{ Média } & - & 7,1 & 6,1 & 1,5 & 3,1 & 4,6 & 17,9 & 6,1 & 2,9 \\
\hline & \multicolumn{9}{|c|}{ 'Sunki' } \\
\hline 120 & 0 & 5,4 & 4,8 & 0,9 & 2,1 & 3,0 & 13,2 & 5,7 & 3,4 \\
\hline 120 & 5 & 5,7 & 4,9 & 0,8 & 2,1 & 3,0 & 13,6 & 5,4 & 3,6 \\
\hline 120 & 10 & 5,0 & 3,6 & 0,8 & 2,0 & 2,8 & 11,4 & 5,5 & 3,1 \\
\hline 120 & 20 & 4,9 & 3,8 & 0,8 & 1,9 & 2,8 & 11,5 & 5,9 & 3,1 \\
\hline 240 & 0 & 5,2 & 4,5 & 0,9 & 2,0 & 2,9 & 12,6 & 5,7 & 3,3 \\
\hline 240 & 5 & 5,2 & 4,4 & 1,0 & 2,0 & 3,0 & 12,6 & 5,5 & 3,3 \\
\hline 240 & 10 & 5,4 & 4,4 & 0,9 & 1,8 & 2,7 & 12,5 & 5,5 & 3,6 \\
\hline 240 & 20 & 5,0 & 4,0 & 0,8 & 2,0 & 2,8 & 11,8 & 5,4 & 3,3 \\
\hline Média & - & 5,2 & 4,3 & 0,9 & 2,0 & 2,9 & 12,4 & 5,6 & 3,3 \\
\hline
\end{tabular}

Teste $F\left({ }^{3}\right)$

\begin{tabular}{|c|c|c|c|c|c|c|c|c|}
\hline PE & $100,9^{* *}$ & $81,3^{* *}$ & $101,8^{* *}$ & $150,9^{* *}$ & $173,9^{* *}$ & $131,8^{* *}$ & $31,3^{* *}$ & $44,5^{* *}$ \\
\hline $\mathrm{N}$ & $0,5^{\mathrm{ns}}$ & $0,3^{\text {ns }}$ & $0,7^{\mathrm{ns}}$ & $0,8^{\text {ns }}$ & $0,7^{\mathrm{ns}}$ & $0,1^{\mathrm{ns}}$ & $0,5^{\mathrm{ns}}$ & $3,5^{\mathrm{ns}}$ \\
\hline $\mathrm{Cu}$ & $3,9^{*}$ & $2,9^{*}$ & $2,8^{*}$ & $0,8^{\text {ns }}$ & $1,8^{\text {ns }}$ & $3,2^{*}$ & $0,3^{\text {ns }}$ & $2,1^{\mathrm{ns}}$ \\
\hline $\mathrm{PE}^{*} \mathrm{~N}$ & $1,0^{\text {ns }}$ & $0,1^{\text {ns }}$ & $1,5^{\mathrm{ns}}$ & $0,1^{\text {ns }}$ & $0,1^{\text {ns }}$ & $0,2^{\text {ns }}$ & $0,1^{\text {ns }}$ & $0,7^{\mathrm{ns}}$ \\
\hline $\mathrm{PE}^{*} \mathrm{Cu}$ & $1,8^{\text {ns }}$ & $2,7^{\mathrm{ns}}$ & $1,8^{\text {ns }}$ & $0,1^{\text {ns }}$ & $0,4^{\mathrm{ns}}$ & $1,5^{\mathrm{ns}}$ & $0,6^{\text {ns }}$ & $2,7^{\mathrm{ns}}$ \\
\hline $\mathrm{N}^{*} \mathrm{Cu}$ & $0,9^{\text {ns }}$ & $0,4^{\mathrm{ns}}$ & $0,6^{\mathrm{ns}}$ & $0,7^{\mathrm{ns}}$ & $0,2^{\text {ns }}$ & $0,3^{\text {ns }}$ & $1,1^{\mathrm{ns}}$ & $1,9^{\mathrm{ns}}$ \\
\hline
\end{tabular}

$\left({ }^{1}\right)$ Superior, representa o volume de substrato na camada até de $20 \mathrm{~cm}$ da sacola da muda; inferior, representa o volume de substrato na camada de $20-40 \mathrm{~cm}$ da sacola da muda.

$\left({ }^{2}\right)$ Diâmetro = diâmetro do caule do porta-enxerto e PA/R = razão massa seca total da parte áerea e raiz.

3 ns, ***: não significativo, e significativo ao nível de $5 \%$ e de $1 \%$ respectivamente.

A relação PA/R para 'Pêra/'Sunki' foi de 2,5 e de 2,2. Assim, evidenciou-se resposta ao suprimento de $\mathrm{N}$ em vista do maior aumento de produção de massa seca das mudas. $\mathrm{O} N$, por ser exigido em quantidade elevada e participar de importantes processos metabólicos das plantas, determina o aumento da produção de massa seca de mudas de citros (Vitória et al., 2001; Ruschel et al., 2004; ScivitTARo et al., 2004).

O suprimento de $\mathrm{Cu}$ nas doses de $5-10 \mathrm{mg} \mathrm{L}^{-1}$ promoveu o desenvolvimento das mudas sobre os dois porta-enxertos estudados, também avaliado pela produção de massa seca, diâmetro de caule e altura das plantas, se comparado ao tratamento sem a adição do nutriente (Tabela 2). Na dose de $20 \mathrm{mg} \mathrm{L}^{-1}$ de $\mathrm{Cu}$, houve diminuição do desenvolvimento das mudas, demonstrando o efeito da fitotoxicidade causada pelo excesso de $\mathrm{Cu}$. Esse prejuízo foi menor para a produção de massa seca das mudas nos tratamentos com a dose de $\mathrm{N}$ de $240 \mathrm{mg} \mathrm{L}^{-1}$ (Figura 1). Também, destaca-se que para plantas sobre 'Sunki', que receberam a maior dose de $\mathrm{N}$, a produção máxima de MS total ocorreu com $11,5 \mathrm{mg} \mathrm{L}^{-1}$ de $\mathrm{Cu}$, o que pode ser explicado pela maior demanda do micronutriente quando a produção de MS é maior. 
Tabela 2. Crescimento de mudas de laranjeira 'Pêra' sobre dois porta-enxertos, aos 254 dias de idade após o transplantio, fertirrigadas com diferentes doses de nitrogênio e cobre

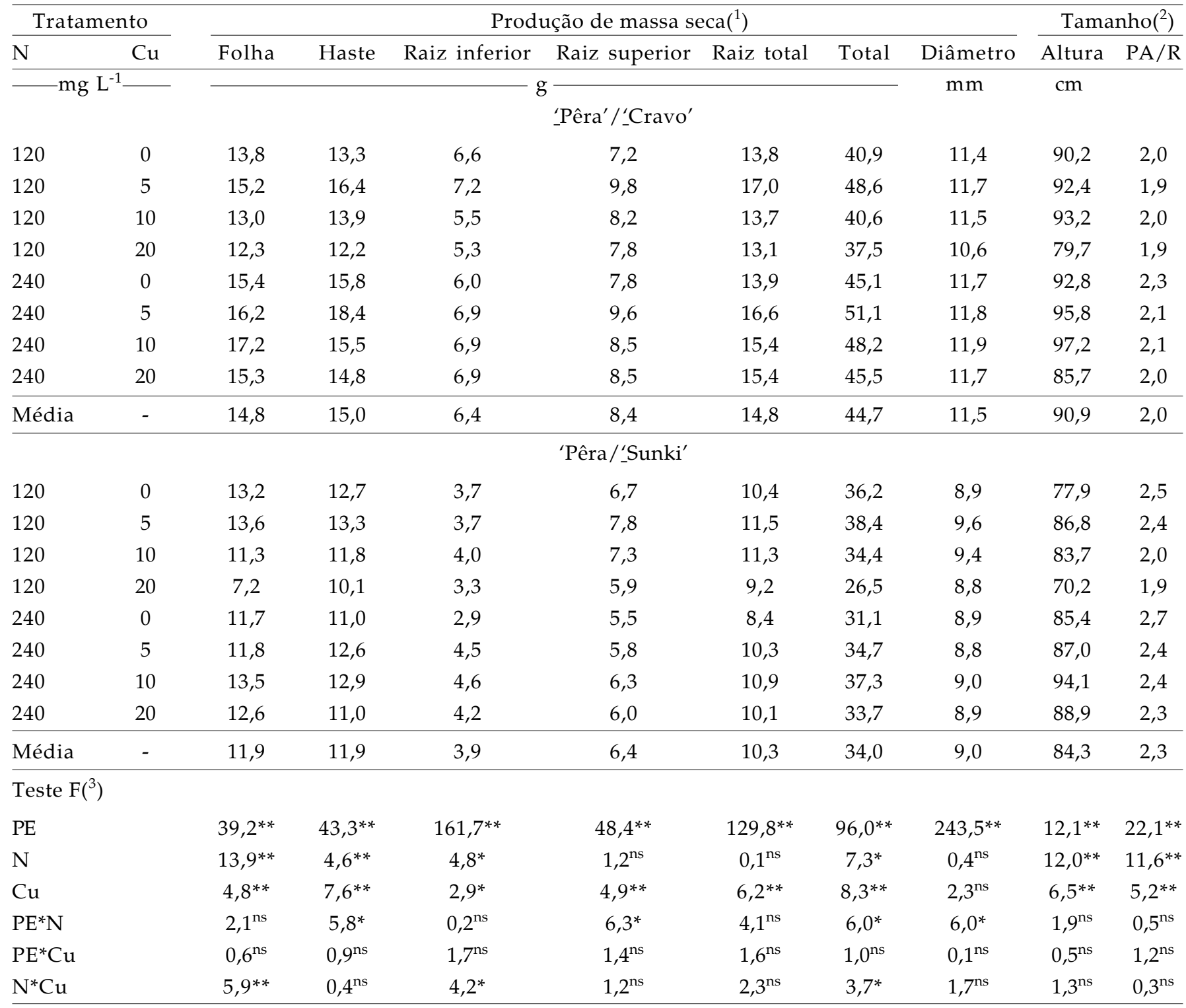

$\left({ }^{1}\right)$ Superior, representa o volume de substrato na camada até de $20 \mathrm{~cm}$ da sacola da muda; Inferior, representa o volume de substrato na camada de $20-40 \mathrm{~cm}$ da sacola da muda.

$\left({ }^{2}\right)$ Diâmetro = diâmetro do caule do porta-enxerto e PA/R = razão massa seca total da parte áerea e raiz.

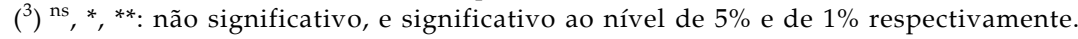

Outro aspecto que deve ser discutido com base nas curvas de resposta estabelecidas na figura 1 , é que para a produção eficiente de mudas de laranjeira 'Pêra' em porta-enxerto de tangerineira 'Sunki', a adubação nitrogenada pode ser mantida em níveis mais baixos comparados àqueles para produção de mudas sobre 'Cravo', caso contrário o suprimento adequado de $\mathrm{Cu}$ torna-se limitante à formação da muda. No campo, o excesso da adubação nitrogenada é referido como causa da deficiência de $\mathrm{Cu}$ induzida nos citros (QuAgGio e PIZA JúnIOR, 2001), o que reitera a maior demanda deste nutriente motivado pelas doses crescentes de $\mathrm{N}$.

Os teores de macro e micronutrientes nas folhas dos porta-enxertos de 'Cravo' foram: $\mathrm{em} \mathrm{g} \mathrm{kg}^{-1}, \mathrm{~N}(38)$, $\mathrm{K}(23), \mathrm{P}(3,2), \mathrm{Ca}(17,5)$ e $\mathrm{Mg}(5,1)$, e em mg kg${ }^{-1}, \mathrm{~B}$ (73), Cu (16), Fe (194), Mn (98) e Zn (18); para 'Sunki' foram: em $\mathrm{g} \mathrm{kg}^{-1}, \mathrm{~N}(32), \mathrm{K}(20), \mathrm{P}(2,2), \mathrm{Ca}(20,8)$ e $\mathrm{Mg}$ $(4,5)$, e em mg kg-1 $, \mathrm{B}(60), \mathrm{Cu}(13), \mathrm{Fe}(162), \mathrm{Mn}(83) \mathrm{e}$ $\mathrm{Zn}$ (12). O acúmulo médio de $\mathrm{N}$ (folha + raiz) foi maior para o 'Cravo' (430 mg por planta de $\mathrm{N}$; $n=6$ ) e menor 
para a 'Sunki' (252 mg por planta de $\mathrm{N} ; n=6)$, na dose de $5 \mathrm{mg} \mathrm{L}^{-1}$ de $\mathrm{Cu}$, enquanto o acúmulo de $\mathrm{Cu}$ (folha + raiz) foi crescente até a dose de $20 \mathrm{mg} \mathrm{L}^{-1}$ de $\mathrm{Cu}$. Verificaram-se quantidades até de $0,30 \mathrm{mg}$ por planta de $\mathrm{Cu}$ para o 'Cravo' nas maiores doses de $\mathrm{N}$ e de $\mathrm{Cu}$ aplicadas na fertirrigação (Dados não apresentados).

A diferença varietal entre porta-enxertos, constatadas anteriormente à enxertia das mudas, foi também evidente na avaliação da concentração foliar de $\mathrm{N}, \mathrm{Ca}, \mathrm{Cu}, \mathrm{Fe}, \mathrm{Mn}$ e $\mathrm{Zn}$ das mudas enxertadas

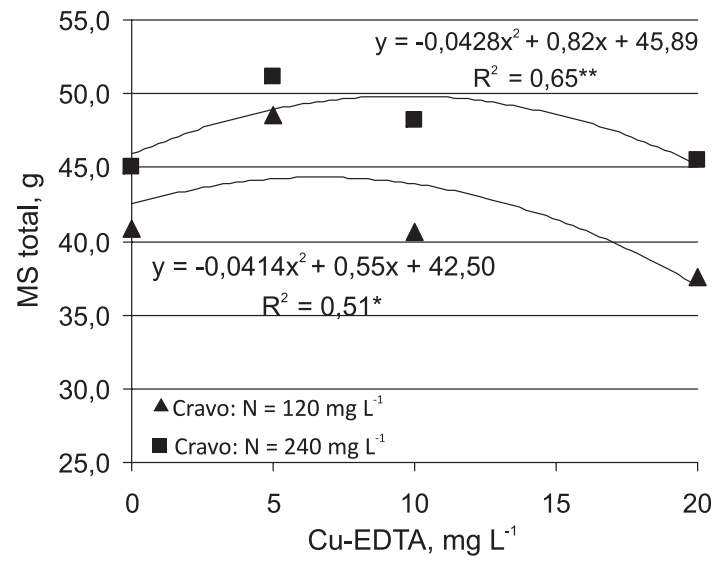

$(P<0,05$; Tabela 3). Ainda, considerando a discussão da maior demanda de $\mathrm{Cu}$ por laranjeira 'Pêra' sobre 'Sunki', é possível que outros micronutrientes limitem o desenvolvimento das mudas nesse porta-enxerto, em resposta ao suprimento em excesso de $\mathrm{N}$, uma vez que foram observadas menores concentrações médias nas folhas para a maior dose de $\mathrm{N}$ testada (N240), como segue, em mg kg-1, Cu (13), Fe (148), Mn (88) e Zn (17) (Tabela 3). Essa resposta pôde ser associada à ocorrência dos sintomas visuais da deficiência de Mn nas mudas sobre 'Sunki'.

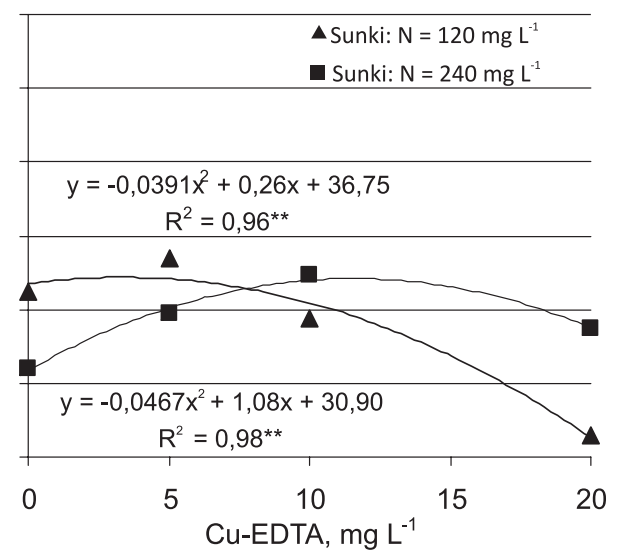

Figura 1. Produção de massa seca total de mudas de laranjeira 'Pêra' sobre porta-enxertos de 'Cravo' e 'Sunki' fertirrigadas com diferentes doses de $\mathrm{N}$ e $\mathrm{Cu}$, avaliada 254 dias após o transplantio no viveiro. Dados agrupados dentro de portaenxertos e doses de $\mathrm{N}(n=6)$.

As concentrações de nutrientes nas raízes das porções superior e inferior da sacola das mudas sobre limoeiro 'Cravo' foram menores comparado àquelas sobre 'Sunki' (Tabelas 4 e 5 respectivamente). O suprimento de $\mathrm{Cu}$ causou aumento da concentração deste nutriente no tecido das raízes. Foram observados teores que variaram de $12 \mathrm{mg} \mathrm{kg}^{-1}$ a $95 \mathrm{mg} \mathrm{kg}^{-1}$ de Cu nas raízes da parte superior da sacola e de $19 \mathrm{mg} \mathrm{kg}^{-1}$ a $45 \mathrm{mg} \mathrm{kg}^{-1}$ de $\mathrm{Cu}$ nas raízes da parte inferior para ambos os porta-enxertos $(P<0,01$; Tabelas 4 e 5$)$. A adição de $\mathrm{Cu}$ causou um decréscimo significativo $(P<0,05)$ nos teores de $\mathrm{Mn}$ nas raízes coletadas nas duas camadas da sacola.

A maior atividade de um íon na solução do substrato pode diminuir a atividade de outro e consequentemente a diminuição da absorção radicular. Como exemplo, o aumento da concentração de $\mathrm{Cu}$ em solução nutritiva determinou a redução da absorção de Zn, Fe e Mn por seedlings de tangerineira Cleópatra e citrumeleiro Swingle (Alva e CHEN, 1995). Esse efeito sobre equilíbrio iônico em solução pôde também ser verificado com a aplicação de sulfato de cobre (de 0 a $400 \mathrm{mg} \mathrm{kg}^{-1}$ de $\mathrm{Cu}$ ) em amostras de solo da Flórida (HuAng e Alva, 1999). Os referidos autores verificaram que a distribuição de várias formas químicas de $\mathrm{Fe}, \mathrm{Mn}, \mathrm{Zn}$ e Al (trocável, adsorvida, ligada a complexos orgânicos, precipitada e residual) foram influenciadas, ocorrendo diminuição da absorção de nutrientes por seedlings de Swingle.

A competição entre esses micronutrientes metálicos pelos sítios de absorção na membrana celular também ocorre. Assim, o trabalho de SMITH e SPECHT (1952), desenvolvido com seedlings de citros para estudar a ocorrência da clorose em pomares da Flórida em vista da deficiência de $\mathrm{Fe}$, onde se verificava acúmulo de $\mathrm{Cu}$, Zn e Mn na camada superfical do solo, demonstrou a inibição do crescimento vegetal com o aumento do $\mathrm{Cu}$ na solução nutritiva, associado também à ocorrência de sintomas visuais da deficiência de Mn.

Em função do maior vigor do porta-enxerto de limoeiro 'Cravo', sobre o qual as produções de massa seca da parte aérea e das raízes de laranjeira 'Pêra' foram superiores aos da 'Sunki', houve correspondência do acúmulo de $\mathrm{N}$ e $\mathrm{Cu}$ nos tecidos vegetais, isto é, a maior massa correspondeu à maior absorção de nitrogênio. Assim, mudas (excluindo hastes) sobre 'Cravo' absorveram $947 \mathrm{mg}$ e $812 \mathrm{mg}$ de $\mathrm{N}$ nas condições $\mathrm{N}(240)$ e $\mathrm{N}(120)$, respectivamente, enquanto da mesma forma, aquelas sobre 'Sunki' absorveram $695 \mathrm{mg}$ e $630 \mathrm{mg}$ de N (valores obtidos com dados das Tabelas 3 a 5). 
Tabela 3. Concentração de macro e micronutrientes em folhas de mudas de laranjeira 'Pêra' sobre dois porta-enxertos, aos 254 dias de idade após o transplantio, fertirrigadas com diferentes doses de nitrogênio e cobre

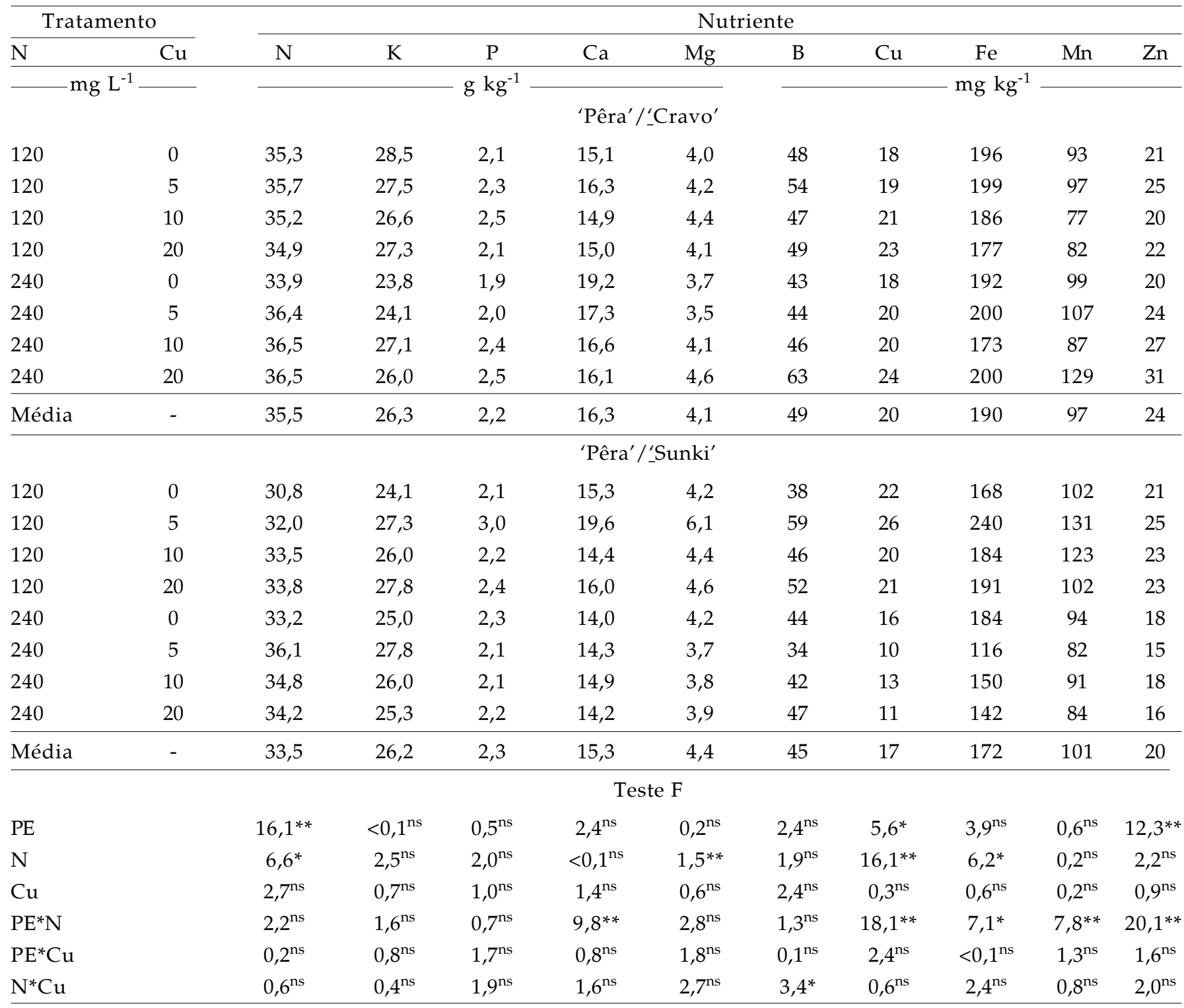

${ }^{\text {ns: }}$ não significativo. * **: significativo aos níveis de $5 \%$ e de $1 \%$ respectivamente.

No caso do cobre, dada a absorção excessiva desse elemento, mesmo associado à menor produção de massa seca das plantas, o acúmulo ocorreu nas maiores doses do nutriente. Assim, observaram-se valores médios nas folhas de $0,26 \mathrm{mg}$ por planta nas mudas de 'Pêra' sobre 'Cravo' e de 0,16 mg por planta naquelas sobre 'Sunki'.

Pelo balanço de nutrientes estimado para mudas de laranjeira 'Valência', realizado por BoAventura et al. (2004), notou-se que a absorção de $\mathrm{N}$ foi cerca de $1.500 \mathrm{mg}$ por planta e de $\mathrm{Cu}$ foi cerca de $1 \mathrm{mg}$ por planta; a solução de fertirrigação continha $196 \mathrm{mg} \mathrm{L}^{-1}$ de $\mathrm{N}$ e $0,13 \mathrm{mg} \mathrm{L}^{-1}$ de $\mathrm{Cu}$. No caso do N, o valor pode ser considerado similar ao do presente estudo, uma vez que não foram somados os conteúdos das hastes dos porta-enxertos no momento da desbrota e também das hastes das mudas por ocasião da finalização aos 254 dias. Notase que, no trabalho de BoAventura et al. (2004), na ocasião da enxertia dos porta-enxertos (100 dias após o transplantio), cerca de $35 \%$ da matéria seca acumulada por plantas sobre 'Cravo' estavam nas folhas e $40 \%$ no caule.

$\mathrm{O}$ acúmulo de $\mathrm{Cu}$ nas mudas de 'Pêra' foi bastante superior àqueles também reportados por esses autores. 
Tabela 4. Concentração de macro e micronutrientes nas raízes de mudas de laranjeira 'Pêra' sobre dois porta-enxertos aos 254 dias de idade após o transplantio, na porção superior $\left({ }^{1}\right)$ da sacola da muda, fertirrigadas com diferentes doses de nitrogênio e cobre

\begin{tabular}{|c|c|c|c|c|c|c|c|c|c|c|c|}
\hline \multicolumn{2}{|c|}{ Tratamento } & \multicolumn{10}{|c|}{ Nutriente } \\
\hline $\mathrm{N}$ & $\mathrm{Cu}$ & $\mathrm{N}$ & $\mathrm{K}$ & $\mathrm{P}$ & $\mathrm{Ca}$ & $\mathrm{Mg}$ & $\mathrm{B}$ & $\mathrm{Cu}$ & $\mathrm{Fe}$ & $\mathrm{Mn}$ & $\mathrm{Zn}$ \\
\hline \multirow[t]{2}{*}{$-\mathrm{m}$} & - & 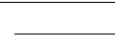 & 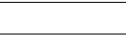 & $\mathrm{g} \mathrm{kg}^{-1}$ & 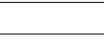 & - & 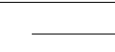 & 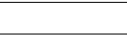 & $\mathrm{mg} \mathrm{kg}$ & & \\
\hline & \multicolumn{11}{|c|}{ 'Pêra' /_Cravo' } \\
\hline 120 & 0 & 23,3 & 16,4 & 3,5 & 8,0 & 3,5 & 41 & 16 & 968 & 298 & 34 \\
\hline 120 & 5 & 22,3 & 11,0 & 3,0 & 8,6 & 3,9 & 37 & 38 & 1548 & 268 & 46 \\
\hline 120 & 10 & 22,8 & 11,9 & 3,5 & 8,5 & 3,8 & 47 & 63 & 1522 & 265 & 47 \\
\hline 120 & 20 & 22,0 & 9,4 & 2,6 & 7,3 & 3,6 & 43 & 95 & 1650 & 180 & 50 \\
\hline 240 & 0 & 26,1 & 19,7 & 3,7 & 8,6 & 4,2 & 51 & 13 & 1327 & 606 & 47 \\
\hline 240 & 5 & 22,1 & 15,4 & 3,2 & 8,9 & 3,8 & 44 & 37 & 1583 & 547 & 62 \\
\hline 240 & 10 & 21,6 & 8,7 & 3,3 & 8,7 & 3,3 & 36 & 51 & 1132 & 337 & 56 \\
\hline 240 & 20 & 23,5 & 8,7 & 3,5 & 8,0 & 3,5 & 42 & 93 & 1413 & 338 & 51 \\
\hline \multirow[t]{2}{*}{ Média } & - & 22,9 & 12,7 & 3,3 & 8,3 & 3,7 & 43 & 51 & 1393 & 355 & 49 \\
\hline & \multicolumn{11}{|c|}{ 'Pêra'/'Sunki' } \\
\hline 120 & 0 & 20,6 & 17,1 & 3,4 & 6,1 & 4,2 & 31 & 12 & 1159 & 285 & 35 \\
\hline 120 & 5 & 25,8 & 25,2 & 3,4 & 5,3 & 4,7 & 39 & 32 & 1698 & 366 & 49 \\
\hline 120 & 10 & 25,3 & 22,5 & 3,7 & 5,9 & 4,2 & 25 & 33 & 956 & 358 & 64 \\
\hline 120 & 20 & 24,7 & 21,0 & 3,6 & 5,5 & 3,9 & 33 & 53 & 1058 & 355 & 60 \\
\hline 240 & 0 & 27,9 & 22,9 & 3,4 & 7,1 & 4,5 & 39 & 11 & 1855 & 409 & 69 \\
\hline 240 & 5 & 24,7 & 19,8 & 3,3 & 7,5 & 4,8 & 36 & 33 & 1409 & 431 & 51 \\
\hline 240 & 10 & 25,5 & 22,9 & 3,5 & 7,2 & 4,9 & 41 & 43 & 1813 & 433 & 65 \\
\hline 240 & 20 & 26,3 & 23,1 & 3,4 & 7,2 & 4,9 & 33 & 58 & 1655 & 362 & 75 \\
\hline \multirow[t]{2}{*}{ Média } & - & 25,1 & 21,8 & 3,4 & 6,5 & 4,5 & 35 & 34 & 1450 & 375 & 58 \\
\hline & \multicolumn{11}{|c|}{ Teste F } \\
\hline PE & & $29,0^{* *}$ & $166,8^{* *}$ & $1,4^{\mathrm{ns}}$ & $64,7^{* *}$ & $47,7^{* *}$ & $17,5^{* *}$ & $51,7^{* *}$ & $0,4^{\mathrm{ns}}$ & $0,7^{\mathrm{ns}}$ & $4,5^{*}$ \\
\hline $\mathrm{N}$ & & $11,1^{* *}$ & $1,4^{\mathrm{ns}}$ & $0,2^{\text {ns }}$ & $18,8^{* *}$ & $4,7^{*}$ & $2,4^{\mathrm{ns}}$ & $<0,1^{\mathrm{ns}}$ & $4,6^{*}$ & $33,0^{* *}$ & $6,6^{*}$ \\
\hline $\mathrm{Cu}$ & & $0,7^{\mathrm{ns}}$ & $4,7^{* *}$ & $1,0^{\text {ns }}$ & $1,5^{\mathrm{ns}}$ & $1,4^{\mathrm{ns}}$ & $0,5^{\mathrm{ns}}$ & $126,0^{* *}$ & $1,2^{\text {ns }}$ & $3,6^{*}$ & $1,8^{\mathrm{ns}}$ \\
\hline$P E^{*} \mathrm{~N}$ & & $2,5^{\mathrm{ns}}$ & $<0,1^{\mathrm{ns}}$ & $2,3^{\text {ns }}$ & $5,8^{*}$ & $6,0^{*}$ & $1,24^{\mathrm{ns}}$ & $3,3^{\text {ns }}$ & $7,6^{* *}$ & $8,4^{* *}$ & $0,1^{\mathrm{ns}}$ \\
\hline $\mathrm{PE}^{*} \mathrm{Cu}$ & & $4,6^{* *}$ & $12,9^{* *}$ & $1,1^{\mathrm{ns}}$ & $1,0^{\mathrm{ns}}$ & $0,7^{\mathrm{ns}}$ & $0,8^{\text {ns }}$ & $12,8^{* *}$ & $1,4^{\mathrm{ns}}$ & $4,2^{*}$ & $1,1^{\mathrm{ns}}$ \\
\hline $\mathrm{N}^{*} \mathrm{Cu}$ & & $10,8^{* *}$ & $3,4^{*}$ & $0,6^{\mathrm{ns}}$ & $0,3^{\text {ns }}$ & $1,0^{\mathrm{ns}}$ & $1,1^{\mathrm{ns}}$ & $0,1^{\mathrm{ns}}$ & $2,0^{\mathrm{ns}}$ & $2,2^{\mathrm{ns}}$ & $1,0^{\mathrm{ns}}$ \\
\hline
\end{tabular}

$\left({ }^{1}\right)$ Porção superior, representa o volume de substrato na camada até de $20 \mathrm{~cm}$ da sacola da muda.

ns: não significativo. ${ }^{*},{ }^{* *}$ : significativo ao nível de $5 \%$ e de $1 \%$ respectivamente.

Pôde-se estimar que o acúmulo de Mn pelas folhas das mudas foi máxima na dose de aproximadamente $5 \mathrm{mg} \mathrm{L}^{-1}$ de $\mathrm{Cu}$ para 'Cravo' e 8,5 $m g L^{-1}$ de Cu para 'Sunki' (Figura 2) e que na dose de $20 \mathrm{mg} \mathrm{L}^{-1}$ de $\mathrm{Cu}$ houve decréscimo acentuado da absorção do referido micronutriente, o que representa o mesmo para o Mn nas raízes.

A avaliação do pegamento das borbulhas para os dois porta-enxertos estudados comprovou a dificuldade de enxertia de 'Pêra' sobre a tangerineira 'Sunki' no viveiro, cuja porcentagem de pegamento foi em média $66 \%$, enquanto no
'Cravo' foi $85 \%$ (Figura 3). O excesso de $\mathrm{Cu}$ aplicado na fertirigação causou um decréscimo significativo do pegamento de borbulhas de 'Pêra'. Por outro lado, o sucesso na enxertia sobre a 'Sunki' parece ser também influenciado em condições de baixa disponibilidade de $\mathrm{Cu}$, pois neste porta-enxerto a porcentagem máxima de pegamento de borbulhas $(75 \%)$ ocorreu na dose de $8,9 \mathrm{mg} \mathrm{L}^{-1}$ do nutriente. Para o limoeiro 'Cravo', o valor máximo foi de $88 \%$ na dose de $2,8 \mathrm{mg} \mathrm{L}^{-1}$ de $\mathrm{Cu}$ (Figura 3). Não foram constatados resultados de pesquisa acerca desse efeito sobre o pegamento das borbulhas no viveiro. 
Tabela 5. Concentração de macro e micronutrientes nas raízes de mudas de laranjeira 'Pêra' sobre dois porta-enxertos aos 254 dias de idade após o transplantio, na porção inferior $\left({ }^{1}\right)$ da sacola da muda, fertirrigadas com diferentes doses de nitrogênio e cobre

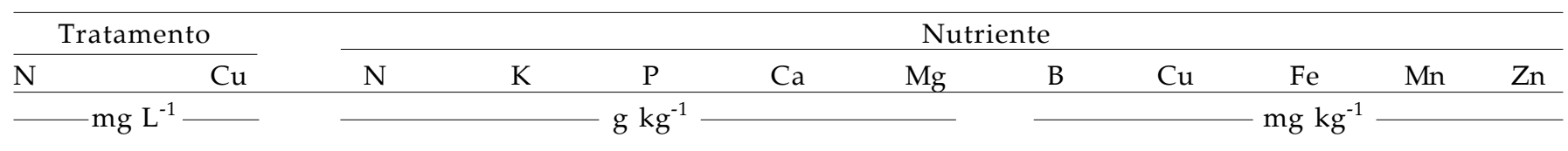

\begin{tabular}{|c|c|c|c|c|c|c|c|c|c|c|c|}
\hline 120 & 0 & 24,6 & 20,6 & 2,9 & 6,6 & 4,0 & 40 & 19 & 834 & 279 & 22 \\
\hline 120 & 5 & 23,8 & 15,9 & 2,5 & 6,0 & 3,7 & 28 & 23 & 798 & 231 & 20 \\
\hline 120 & 10 & 23,5 & 15,4 & 3,0 & 6,8 & 4,2 & 27 & 38 & 940 & 231 & 30 \\
\hline 120 & 20 & 24,4 & 12,8 & 2,7 & 6,3 & 3,9 & 31 & 45 & 1001 & 178 & 25 \\
\hline 240 & 0 & 26,1 & 20,3 & 3,0 & 7,2 & 4,5 & 50 & 19 & 899 & 455 & 26 \\
\hline 240 & 5 & 27,6 & 21,3 & 3,1 & 7,7 & 4,9 & 49 & 31 & 1265 & 502 & 38 \\
\hline 240 & 10 & 24,0 & 11,2 & 3,3 & 8,7 & 4,7 & 58 & 37 & 1090 & 371 & 40 \\
\hline 240 & 20 & 25,2 & 12,4 & 3,3 & 7,2 & 4,4 & 46 & 41 & 975 & 270 & 31 \\
\hline \multirow[t]{2}{*}{ Média } & - & 24,9 & 16,2 & 3,0 & 7,1 & 4,3 & 41 & 32 & 975 & 315 & 29 \\
\hline & \multicolumn{11}{|c|}{ 'Pêra' /'Sunki' } \\
\hline 120 & 0 & 25,4 & 25,9 & 3,5 & 5,0 & 4,4 & 41 & 25 & 1421 & 379 & 27 \\
\hline 120 & 5 & 28,1 & 32,3 & 3,4 & 4,5 & 4,7 & 45 & 33 & 1598 & 393 & 32 \\
\hline 120 & 10 & 26,2 & 24,0 & 3,5 & 5,6 & 4,0 & 47 & 40 & 1125 & 374 & 39 \\
\hline 120 & 20 & 27,4 & 26,6 & 3,5 & 4,6 & 4,1 & 44 & 27 & 1228 & 345 & 38 \\
\hline 240 & 0 & 29,0 & 21,8 & 3,4 & 7,0 & 5,2 & 49 & 21 & 1479 & 462 & 33 \\
\hline 240 & 5 & 28,4 & 25,7 & 3,3 & 5,5 & 4,7 & 47 & 22 & 1426 & 393 & 37 \\
\hline 240 & 10 & 27,7 & 30,6 & 3,3 & 6,3 & 5,4 & 50 & 41 & 1856 & 495 & 40 \\
\hline 240 & 20 & 27,8 & 29,4 & 3,2 & 5,2 & 4,4 & 43 & 39 & 1520 & 340 & 39 \\
\hline \multirow[t]{2}{*}{ Média } & - & 27,5 & 27,0 & 3,4 & 5,5 & 4,6 & 46 & 31 & 1457 & 398 & 36 \\
\hline & \multicolumn{11}{|c|}{ Teste F } \\
\hline PE & & $11,2^{* *}$ & $89,4^{* *}$ & $11,5^{* *}$ & $56,5^{* *}$ & $3,3^{\text {ns }}$ & $8,3^{* *}$ & $<0,1^{\mathrm{ns}}$ & $38,0^{* *}$ & $19,2^{* *}$ & $9,9^{* *}$ \\
\hline $\mathrm{N}$ & & $4,1^{*}$ & $0,1^{\mathrm{ns}}$ & $0,6^{\mathrm{ns}}$ & $30,0^{* *}$ & $13,7^{* *}$ & $50,5^{* *}$ & $<0,1^{\mathrm{ns}}$ & $6,3^{*}$ & $33,5^{* *}$ & $8,5^{* *}$ \\
\hline $\mathrm{Cu}$ & & $0,7^{\mathrm{ns}}$ & $2,2^{\text {ns }}$ & $0,5^{\mathrm{ns}}$ & $4,9^{* *}$ & $1,0^{\mathrm{ns}}$ & $1,8^{\mathrm{ns}}$ & $16,4^{* *}$ & $0,5^{\mathrm{ns}}$ & $6,9^{* *}$ & $3,9^{*}$ \\
\hline $\mathrm{PE}^{*} \mathrm{~N}$ & & $<0,1^{\mathrm{ns}}$ & $<0,1^{\mathrm{ns}}$ & $5,7^{*}$ & $0,4^{\mathrm{ns}}$ & $0,1^{\mathrm{ns}}$ & $26,7^{* *}$ & $<0,1^{\mathrm{ns}}$ & $0,2^{\mathrm{ns}}$ & $10,1^{* *}$ & $2,0^{\text {ns }}$ \\
\hline $\mathrm{PE}^{*} \mathrm{Cu}$ & & $0,1^{\mathrm{ns}}$ & $5,5^{*}$ & $0,2^{\mathrm{ns}}$ & $1,3^{\text {ns }}$ & $0,4^{\mathrm{ns}}$ & $1,0^{\mathrm{ns}}$ & $2,3^{\mathrm{ns}}$ & $0,3^{\text {ns }}$ & $1,8^{\mathrm{ns}}$ & $0,3^{\text {ns }}$ \\
\hline $\mathrm{N}^{*} \mathrm{Cu}$ & & $0,3^{\text {ns }}$ & $0,5^{\mathrm{ns}}$ & $0,2^{\mathrm{ns}}$ & $0,5^{\mathrm{ns}}$ & $0,5^{\mathrm{ns}}$ & $1,8^{\mathrm{ns}}$ & $0,4^{\mathrm{ns}}$ & $1,2^{\mathrm{ns}}$ & $1,4^{\mathrm{ns}}$ & $0,7^{\text {ns }}$ \\
\hline
\end{tabular}

$\left({ }^{1}\right)$ Porção inferior, representa o volume de substrato na camada de $20-40 \mathrm{~cm}$ da sacola da muda.

ns: não significativo. ${ }^{*}, * *$ : significativo ao nível de $5 \%$ e de $1 \%$ respectivamente.
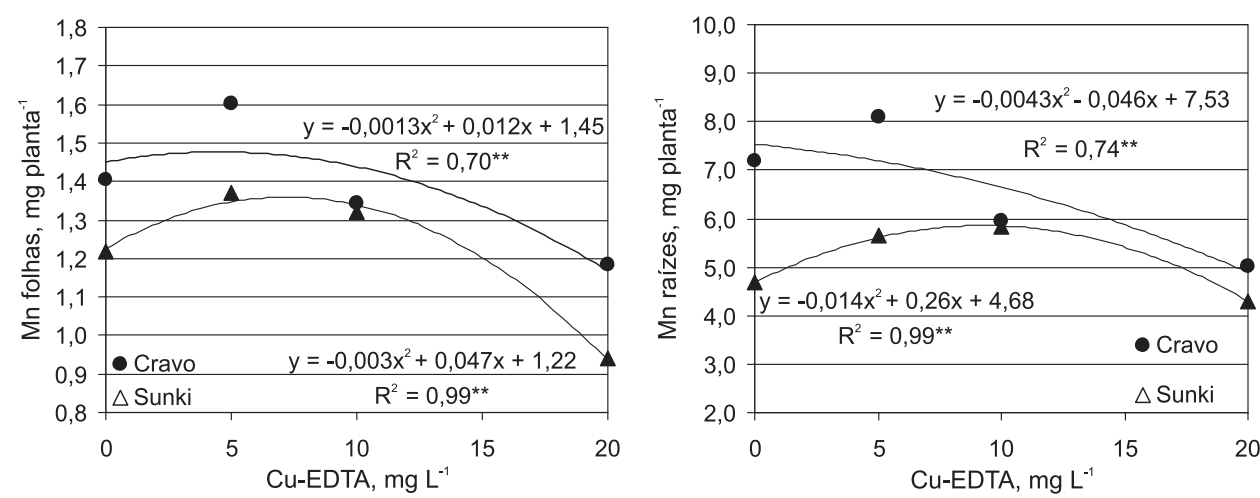

Figura 2. Acúmulo de Mn nas folhas e raízes de mudas de laranjeira 'Pêra' sobre porta-enxertos de 'Cravo' e 'Sunki' fertirrigadas com diferentes doses de $\mathrm{Cu}$, avaliado 254 dias após o transplantio no viveiro. Dados agrupados dentro de doses de $\mathrm{N}(n=6)$. 


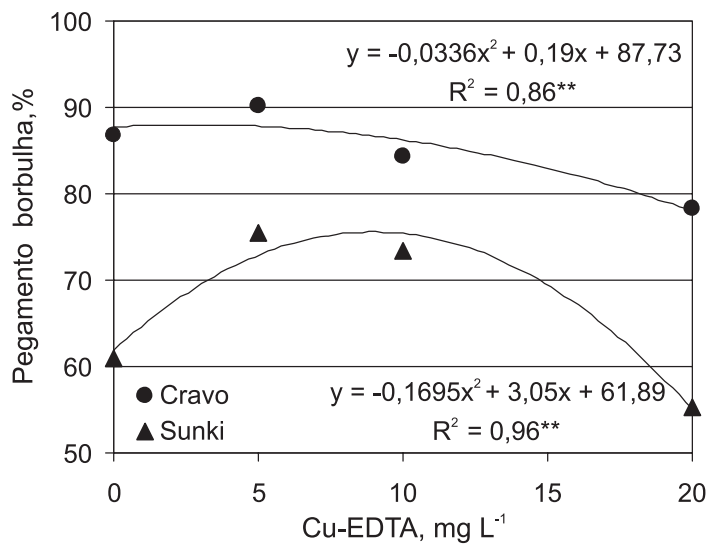

Figura 3. Pegamento de borbulhas de laranjeira 'Pêra' sobre dois porta-enxertos fertirrigados com diferentes doses de $\mathrm{Cu}$, avaliado 92 dias após a enxertia no viveiro. Dados agrupados dentro de porta-enxertos e doses de $\mathrm{N}(n=6)$.

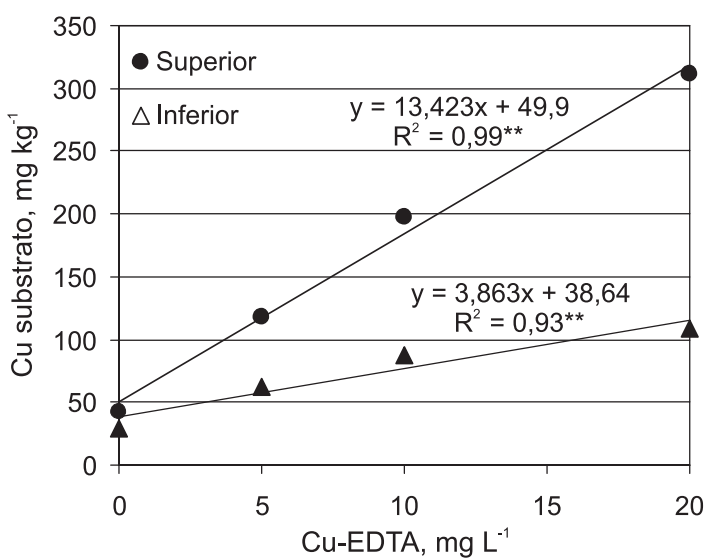

Figura 4. Teores de $\mathrm{Cu}$ no substrato em duas camadas da sacola de produção, aos 254 dias após o transplatio de mudas de citros fertirrigadas com diferentes doses de nitrogênio e cobre. Superior, representa o volume de substrato na camada até de $20 \mathrm{~cm}$, e Inferior, representa o volume na camada de $20-40 \mathrm{~cm}$ da sacola da muda.

A toxicidade de cobre causa inibição do crescimento das plantas e prejudica importantes processos celulares como fotossíntese e respiração, pela inibição da atividade de grande número de enzimas e prejuízos à manutenção da integridade de membranas (Fernandes e Henriques, 1991; Yruela, 2005). Assim, é possível afirmar que esses efeitos, diretos e/ou indiretos, sobre os processos bioquímicos da planta estariam comprometendo a integridade de tecidos e a produção de energia responsáveis pelo desenvolvimento da gema enxertada. Fernandes e Henriques (1991) ainda descrevem que a toxicidade de $\mathrm{Cu}$ induz a produção de etileno em algas do gênero Spirodella. O acúmulo desse hormônio poderia estar associado à senescência dos tecidos na região de enxertia, o que diminuiria o pegamento de borbulhas.
Os teores de $\mathrm{Cu}$ no substrato foram maiores na camada superior da sacola $(P<0,01$; Figura 4$)$. Embora o volume de água aplicado na fertirrigação tenha sido suficiente para molhar todo o volume de substrato da sacola, o incremento da concentração desse elemento foi cerca de três vezes maior na camada superior $\left(65 \mathrm{mg} \mathrm{kg}^{-1}\right.$ na camada superior e $19 \mathrm{mg} \mathrm{kg}^{-1}$ na camada inferior da sacola, Figura 4).

As reações de adsorção do $\mathrm{Cu}$ na superfície de colóides do solo são bastante fortes e ocorrem pela formação de complexos $\mathrm{Cu}$-ligante de alta energia (Ferreira e Cruz, 1991). Assim, a disponibilidade desse elemento para as plantas é uma função da contribuição e da composição da fração orgânica do meio de crescimento. Uma vez que o substrato à base de casca de pínus possui grande proporção de lignina e outros compostos ogânicos como resinas e taninos (MARTINEZ, 2002), é possível afirmar que o $\mathrm{Cu}$ foi adsorvido na camada superior do substrato. Como o processo de dessorção desse metal é mais lento, uma menor quantidade foi transportada para a camada inferior, o que então explica as diferenças observadas também para os maiores teores de $\mathrm{Cu}$ nas raízes das mudas retiradas da porção superior da sacola (Tabelas 4 e 5).

Os terores de $\mathrm{Fe}, \mathrm{Mn}$ e $\mathrm{Zn}$ variaram significativamente $(P>0,07)$ entre as camadas superior e inferior do substrato. Verificaram-se, em $\mathrm{mg} \mathrm{kg}^{-1}$, os seguintes teores médios para todos os tratamentos testados: Fe (12), Mn (201) e Zn (39).

\section{CONCLUSÕES}

1. A solução de fertirrigação de $120 \mathrm{mg} \mathrm{L}^{-1}$ de $\mathrm{N}$ promove desenvolvimento adequado de ambos os porta-enxertos estudados antes da enxertia. Para as mudas da laranjeira 'Pêra', obtém-se o mesmo resultado com a solução de fertirrigação composta de $240 \mathrm{mg} \mathrm{L}^{-1}$ de N e 5 a $10 \mathrm{mg} \mathrm{L}^{-1}$ de Cu-EDTA; porém, o efeito é depressivo para as plantas na concentração de $20 \mathrm{mg} \mathrm{L}^{-1}$ de Cu-EDTA.

2. O pegamento de borbulhas é ótimo nas doses intermediárias de $\mathrm{Cu}$ na fertirrigação. Destaca-se que a demanda de $\mathrm{Cu}$ é maior para mudas sobre 'Sunki' na maior dose de $\mathrm{N}$ e o excesso desse elemento reduz a absorção de $\mathrm{Mn}$ pelas plantas.

3. Os teores de $\mathrm{Cu}$ foram maiores para as raízes na porção superior do recipiente de produção das mudas, o que coincide com a maior adsorção de $\mathrm{Cu}$ no substrato ocorrida também na mesma camada, se comparada com a porção inferior do recipiente, com máximo acima de $300 \mathrm{mg} \mathrm{kg}^{-1}$ de $\mathrm{Cu}$. 


\section{AGRADECIMENTOS}

Os autores agradecem aos Engenheiros Agrônomos Christiano César Dibbern Graf, Marcelo Zanetti e Rafael Augusto Fadel Bordignon, da Citrograf Mudas, pelo apoio ao desenvolvimento do experimento no viveiro.

\section{REFERÊNCIAS}

ALMEIDA, T.R.P.; LEONEL, S.; GRASSI FILHO, H. Análise do crescimento de mudas cítricas em função do substrato e do fornecimento de cobre II. In: CONGRESSO BRASILEIRO DE CIÊNCIA DOSOLO, 31., 2007, Gramado - RS. Anais... Gramado: Sociedade Brasileira de Ciência do Solo, 2007a. (CD-Rom)

ALMEIDA, T.R.P.; LEONEL, S.; GRASSI FILHO, H. Crescimento de mudas cítricas em substrato de fibra de coco e o fornecimento de cobre via fertirrigação e foliar. In: CONGRESSO BRASILEIRO DE CIÊNCIA DO SOLO, 31., 2007, Gramado - RS. Anais... Gramado: Sociedade Brasileira de Ciência do Solo, 2007b. (CD-Rom)

ALVA, A.K.; CHEN, Q. Effects of external copper concentrations on uptake of trace elements by citrus seedlings. Soil Science, v.159, p.59-64, 1995.

BATAGLIA, O.C.; FURLANI, A.M.C.; TEIXEIRA, J.P.F.; FURLANI, P.R.; GALLO, J.R. Métodos de análise química de plantas. Campinas: Instituto Agronômico, 1983. 48 p. (Circular n. 78)

BATAGLIA, O.C.; FURLANI, P.R.; FERRAREZI, R.S.; MEDINA, C.L. Padrão nutricional de mudas de citros. Araraquara: Vivecitrus/Conplant, 2008. 40 p.

BOAVENTURA, P.R.R. Demanda por nutrientes de portaenxertos e mudas cítricas produzidas em substratos em ambiente protegido. 2003. 62 f. Dissertação (Mestrado em Gestão dos Recursos Agroambientais) - Instituto Agronômico, Campinas.

BOAVENTURA, P.R.R.; QUAGGIO, J.A.; ABREU, M.F. Balanço de nutrientes na produção de mudas cítricas cultivadas em substrato. Revista Brasileira de Fruticultura, v. 26, n. 2, p. 300-305, 2004.

BORDIGNON, R.A.F. Fontes de ferro e cobre na produção de porta-enxertos cítricos em substrato. 2008. 47 f. Dissertação (Mestrado em Gestão dos Recursos Agroambientais) - Instituto Agronômico, Campinas.

CARVALHO, S.A. Produção de porta-enxertos cítricos sob doses crescentes de nitrato de potássio. Pesquisa Agropecuária Brasileira, v.29, n.1, p.87-90, 1994.

CARVALHO, S.A.; GRAF, C.C.D.; VIOLANTE, A.R. Produção de material básico e propagação. In: MATTOS JÚNIOR, D.; DE NEGRI, J.D.; PIO, R.M.; POMPEU JÚNIOR., J. Citros. Campinas: IAC e Fundag, 2005. p. 279-316.

CARVALHO, S.A.; SOUZA, M. Doses e freqüëncia de aplicação de nitrato de potássio no crescimento do limoeiro 'Cravo' e da tangerineira 'Cleópatra' em bandejas. Pesquisa Agropecuária Brasileira, Brasília, v. 31, n. 12, p. 815-822, 1996.
CASTLE, W.S.; ROUSE, R.E. Total mineral nutrient content of Florida citrus nursery plants. Proceedings of Florida State Horicultural Society, v. 103, p. 42-44. 1990.

COETZEE, J.G.K.; ESSELEM, L.; van ROOYEN, A. Fertilization of nursery trees -alternative method. In: WORLD CONGRESS OF THE INTERNATIONAL SOCIETY OF CITRUS NURSERYMEN, 2., 1993, South Africa. Proceedings... South Africa: International Society of Citrus Nurserymen, 1993. p. 143-150.

DECARLOS NETO, A.; SIQUEIRA, D.L.; PEREIRA, P.R.G.; ALVAREZ V., V.H. Crescimento de porta-enxertos de citros produzidos em tubetes e influenciados por doses de N. Revista Brasileira de Fruticultura, Jaboticabal, v.24, n.1, p.199-203, 2002.

FAO. Food and Agriculture Organization of the United Nations. Disponível em: http:/ / faostat.fao.org. Acesso em maio 2008.

FERNANDES, J.C.; HENRIQUES, F.S. Biochemical, physiological and structural effects of excess copper in plants. The Botanical Review, v.57, p.246-273, 1991.

FERRAREZI, R.S.; BATAGLIA, O.C.; FURLANI, P.R.; SCHAMMASS, E.A. Iron sources for citrus rootstock development grown on pine bark/vermiculite mixed substrate. Scientia Agricola, v. 64, n. 5, p. 520-531, 2007.

FERREIRA, M.E.; CRUZ, M.C.P. Cobre. In: FERREIRA, M.E.; CRUZ, M.C.P. (Ed.). Micronutrientes na agricultura. Piracicaba: Potafos e CNPq, 1991. p. 131-157.

FUNDECITRUS. Viveiros e mudas. Disponível em: <http:/ / www.fundecitrus.com.br/dviveiros_br.html>. Acesso em: 14 out. 2008.

GILBERT, S.G. A biochemical basis for copper-nitrogen balance in tung. Plant Physiology, v.26, n.2, p.298-405, 1951.

GIRARDI, E.A.; MOURÃO FILHO, F.A.A.; GRAF, C.C.D.; OLIC, F.B. Influence of soluble and slow release fertilizers on vegetative growth of containerized citrus nursery trees. Journal of Plant Nutrition, v.28, n.9, p.1465-1480, 2005.

HUANG, B.; ALVA, A.K. Copper amendmends and soil pH affect distribution of different forms of metals and their uptake by Swingle citrumelo seedlings. Journal of Environmental Science and Health, v.34, n.6, p.1065-1082, 1999.

JOAQUIM, D. Produção de mudas de citros em condições controladas : casas de vegetação, substratos e recipientes. Valência (Espanha): UVP - IVIA, 1997. 105 p.

MARTINEZ, P.F. Manejo de substratos para a horticultura. In: ENCONTRO NACIONAL DE SUBSTRATOS PARA PLANTAS, 3., 2002, Campinas. Campinas: Instituto Agronômico, p. 5376. (Documentos IAC, 70)

MATTOS Jr., D.; BOARETTO, R.M.; CORREAA, E.R.L.; ABREU, M.F.; CARVALHO, S.A. Disponibilidade de boro em substrato para produção de porta-enxertos de citros em fase de sementeira. Bragantia, v.67, p.983-989, 2008.

MAUST, B.E.; WILLIAMSON, J.G. Nitrogen nutrition of containerized citrus nursery plants. Journal of American Society for Horticultural Science, v.119, p.195-201, 1994. 
PERIN, J.R.; CARVALHO, S.A.; MATTOS JÚNIOR, D.; CANTARELLA, $\mathrm{H}$. Efeitos de substratos e doses de fertilizante de liberação lenta no teor de clorofila e desenvolvimento vegetativo do limoeitro 'Cravo' em tubetes. Laranja, v.20, n.2, p.457-462, 1999.

POMPEU JUNIOR, J. Porta-enxertos. In: MATTOS Jr., D.; De NEGRI, J.D.; PIO, R.M.; POMPEU JÚNIOR, J. Citros. Campinas: IAC e Fundag, 2005. p. 61-104.

QUAGGIO, J.A.; PIZA Jr., C.T. Frutíferas tropicais. In: Ferreira, M.E.; Cruz, M.C.P.; Raij, B. van; Abreu, C.A. Micronutrientes e elementos tóxicos na agricultura. Jaboticabal: CNPq, Fapesp, Potafos, 2001. p.459-492.

RUSCHEL, J.; CAMARGO, Q.A.C.; BERNARDI, A.C.; CARVALHO, S.A.; MATTOS JÚNIOR, D. Leaf nutrient contents of Rangpur lime rootstock as affected by N, P, Ca and S fertilization. Scientia Agricola, v.61, p.501-506, 2004.

SAS INSTITUTE, Inc. The SAS System - Release 6.12. Cary, NC. 1996.

SCHAFER, G.; SOUZA, P.V.D.; KÖLLER, O.C.; SCHWARZ, S.F. Desenvolvimento vegetativo inicial de porta-enxertos cítricos cultivados em diferentes substratos. Ciência Rural, v.36, n.6, p.1723-1729, 2006.

SCIVITTARO, W.B.; OLIVEIRA, R.P.; RADMANN, E.B. Adubação nitrogenada naformação de porta-enxertos de limoeiro 'Cravo' em tubetes. Revista Brasileira de Fruticultura, v.26, p.131-135, 2004.

SMITH, P.F.; SPECHT, A.W. Heavy-metal accumulation and iron chlorosis of citrus seedlings. Plant Physiology, v.28, p.371-382, 1953.

SONNEVELD, C.; van ELDEREN, C.W. Chemical analysis of peaty growing media by means of water extraction. Communications in Soil Science and Plant Analysis, v.25, p. 3199-3208, 1994.

VITÓRIA, D.P.; DONADIO, L.C.; STUCHI, E.S. Influence of nitrogen and potassium fertilizers in Rangpur lime (Citrus limonia Osbeck) seedlings development. In: PROCEEDINGS OF THE INTERNATIONAL CONGRESS OF CITRUS NURSERYMEN, 6., 2001. Ribeirão Preto. Anais... ISCN, EECB, Fundecitrus, 2001. p.271-274.

WILLIAMSOM, J.G.; CASTLE, W.S. A survey of Florida citrus nurseries. Proceedings of the Florida State Horticultural Society, v.102, p.78-82, 1989.

YRUELA, I. Copper in plants. Brazilian Journal of Plant Physiology, v.17, n.1, p.145-156, 2005. 